\title{
Let us build better boats: an answer to Jeffrey Seeman's "Moving beyond insularity in the history, philosophy, and sociology of chemistry"
}

\author{
Sebastian Fortin ${ }^{1} \cdot$ Olimpia Lombardi $^{1} \cdot J_{\text {Juan Camilo Martínez González }}{ }^{1}$
}

Published online: 12 February 2018

(C) Springer Science+Business Media B.V., part of Springer Nature 2018

In his recent Editorial Article, Seeman (2017) calls for the promotion of collaborative work among different disciplines, focusing on the case of the interaction between chemistry, the history of chemistry and the philosophy of chemistry. From a general viewpoint, it is difficult to disagree with this claim; moreover, the interest of scientists in the history and the philosophy of science is always welcome. However, the devil is in the details: there are several points that, we think, must be discussed more carefully with the aim of arriving at far-reaching conclusions.

\section{Who is interested in isomerism and decoherence?}

Seeman's article reproduces four equations included in our paper "Isomerism and decoherence" (2016) in order to criticize works that he considers too technical to be understood by average readers. However, they are equations that can be read after a first undergraduate course of theoretical quantum mechanics (perhaps with the only exception of Eq. (2), which was taken from Hund's proposal but is conceptually explained immediately below). We appeal to them precisely to introduce the fundamentals of decoherence, assuming that the readers of Foundations of Chemistry do not need to know the formalism. For instance, Eq. (1) is the Hamiltonian of a system of many particles, sum of kinetic and potential energies, with the same form as a classical Hamiltonian. Seeman feels uncomfortable because, being interested in stereochemistry, he cannot read those equations. Of course, this situation is not a scientific limitation, but rather supports the thesis of the ontological autonomy of chemistry proposed by one of us (Lombardi and Labarca 2005; Lombardi 2014): chemistry can develop its knowledge about its own ontology with no need of legitimation coming from physics. In particular, stereochemistry is a highly articulated and successful body of technical knowledge independently of the difficulties of accounting for the disposition

Olimpia Lombardi

olimpiafilo@gmail.com

1 CONICET-University of Buenos Aires, Buenos Aires, Argentina 
of atoms in space with quantum mechanics. Nevertheless, an argument regarding how the phenomenon of decoherence should be interpreted is a formal argument, so the use of formalism is indispensable. If we push the issues in need of technical knowledge beyond the limits of what can be discussed, we would be left with very few interesting matters.

Seeman explicitly asks: "What are the objectives of a scientific publication? I posit that, for a scientist, it is not enough for a paper to get published. Rather, that paper needs to be read, valued and used. That paper needs to make a difference" (p. 7). We wholeheartedly agree with this statement, which applies to our aim in the criticized philosophical paper. We are not "intentionally writing primarily, if not solely, for their own (narrow) niche of specialists" (p. 6). On the contrary, our purpose is precisely to influence chemists regarding the widespread but uncritical assumption about the reduction of molecular chemistry to quantum mechanics on the basis of the phenomenon of decoherence.

\section{What is interdisciplinarity?}

It is quite clear that the specialization of present-day science makes it impossible for a single individual to handle the whole knowledge of her discipline. Therefore, when the matter under scrutiny is very specific and technical, it is necessary to appeal to collaborative work. In fact, far from being "unidisciplinary research" (p. 6), our work (Fortin et al. 2016) was the result of the collaboration between people coming from three different disciplinary origins: Fortin from physics, Lombardi from philosophy and Martínez González from chemistry. However, Seeman does not consider our article as an interdisciplinary work. So, how does he conceive interdisciplinarity?

The history of chemistry and the philosophy of chemistry are not interdisciplinary areas: after having been born in the interstices of different fields, at present they are disciplines in their own rights. In turn, interdisciplinarity is only necessary in the treatment of specific problems that require very varied knowledge; but it is highly probable that the results so obtained are very technical and difficult to be understood by those who are not involved in the particular research. Seeman, on the contrary, seems to believe that interdisciplinarity is what makes a written work understandable by non-specialists. But, then, he is not talking about research literature, but about the so-called "public communication of science": the activity devoted to the presentation of scientific topics to non-experts. Our criticized work did not intend to communicate our results to non-specialists, but to present a well articulated argument that requires specific knowledge to be understood; only in a future stage it may be translated into the language of "science communication".

The journal Foundations of Chemistry $(\mathrm{FOCH})$ gets caught in the net of this conflation between interdisciplinarity and public communication of science when it inherits the criticisms directed to our paper: it is guilty of "disciplinary isolationism: the publication of articles that speak solely to members of one discipline" (p. 5). According to Seeman, in spite that FOCH introduces itself in its website as "an international journal and an interdisciplinary forum in which chemists, biochemists, philosophers, historians, educators and sociologists discuss conceptual and fundamental issues which relate to the 'central science' of chemistry.", it publishes papers whose general content is "nearly incomprehensible to the average reader" (p. 5). But the fact that FOCH is an interdisciplinary forum does not mean that all the works must be interdisciplinary, but that the subject matters may be commented on and discussed from different disciplinary perspectives. And that fact even less 
implies that all the works must be readable by non-specialists: FOCH is a highly-reputed academic journal and not a vehicle of public communication of science.

\section{McCarthyism: a serious accusation}

Up to this point, Seeman's criticisms are confined to scientific research and academic practices. But the article acquires a serious ethical tone when it develops an explicit accusation of McCarthyism to a non-explicitly identified but implicitly identifiable target. Seeman rightly claims that: "Exclusion of scholars from professional or academic circles solely because they do not hold advanced degrees in a particular field or hold an academic position in such a field is also McCarthyism." (p. 4). Since this is a very serious accusation, which certainly inconveniences anybody who might be suspected of being its target, it deserves to be carefully considered.

In, at least, five points of its article, Seeman complains about the exclusion of scholars "solely" due to discrimination (p. 4, p. 9, p. 10), independently of "their skills" (p. 7). But in no place does he consider the possibility that the rejection of certain papers of those he calls "amateur historians of science" are not due solely to plain discrimination, but also to the fact that they do not fulfill certain academic standards required by the journals.

Seeman recalls Brush's (1978) encouragement to hire historians qualified to teach history of science in the context of scientists' training: "Brush apparently was suggesting that chemists were unqualified to teach the history of their own science." (p. 2). Yes, this is what Brush assumes, but what is wrong in it? Science should be taught by scientists, history of science should be taught by historians of science. Of course, it may happen that a particular scholar, trained in science and having devoted much of her life to the practice of science, also becomes a historian of science, professionally able to appeal to the theoretical resources of this discipline. In this case, she has the merit to be hired to teach history of science, but as a historian of science, independently of the fact that she is also a scientist. Amateurism should not be admitted in teaching, both in teaching science and in teaching history of science.

We are not historians, but we can transfer the discussion to the analogous case of the philosophy of science. One of us has a long experience in meetings where scientists and philosophers participate in interesting and fruitful discussions. In many cases, scientists are first-level researchers in their fields, interested in the foundations of their disciplines. Nevertheless, in general they do not publish papers in philosophy of science journals: in the few cases that they do it, either write in collaboration with some philosopher or publish invited review papers about their specialty. On the other hand, in her also long experience as reviewer for philosophy of science journals, in several cases she had to reject works coming from experienced, senior scientists because they did not fulfill the required academic standards. In such amateur works, concepts are usually confused, the context of the discussion is unknown and/or well-known positions are "rediscovered" due to ignoring the relevant literature in the philosophy of science. Although those experiences cannot be automatically transferred to the history of science, they leave open the question about whether certain works coming from "outsiders" from the community of the historians of science are rejected only due to disciplinary discrimination.

Finally, it is interesting to notice the asymmetry of Seeman's discourse. In fact, McCarthyism is found "in the history, philosophy and sociology of science" (p. 10), to the detriment of scientists, but never in the reverse direction. Seeman points out that "an 
examination of the editorial boards of history of chemistry journals or of the names of the leaders of history of chemistry organizations reveals significant disciplinary segregation." (p. 3) since they do not include chemists. Of course, the participation of some scientists in institutions devoted to the history, the philosophy, or the sociology of science would be welcome. But it would be also good to find at least some historian, philosopher, and/ or sociologist of science in the editorial boards of scientific journals or program committees of scientific meetings: this situation is much more exceptional than that denounced by Seeman. If we attend to the concept of complementary science coined by Chang (2004), an author who Seeman likes to quote, the history and the philosophy of science are a continuation of science by other means; this is a good reason for science takes into account these disciplines while respecting their specificity.

Summing up, human knowledge inhabits different "islands", each one with its ecosystem. If we want to improve that knowledge, we have to build better boats to enhance the exchanges between the islands. If, on the contrary, we denounce insularity and reject the existence of the sea between them, the most probable result will be sinking into darkness.

\section{References}

Brush, S.G.: Why chemistry needs history-and how it can get some. J. Coll. Sci. Teach. 7, 288-291 (1978)

Chang, H.: Inventing Temperature. Measurement and Scientific Progress. Oxford University Press, New York (2004)

Fortin, S., Lombardi, O., Martínez González, J.C.: Isomerism and decoherence. Found. Chem. 18, 225-240 (2016)

Lombardi, O.: The ontological autonomy of the chemical world: facing the criticisms. In: Scerri, E., McIntyre, L. (eds.) Philosophy of Chemistry: Growth of a New Discipline, pp. 23-38. Springer, Dordrecht (2014)

Lombardi, O., Labarca, M.: The ontological autonomy of the chemical world. Found. Chem. 7, 125-148 (2005)

Seeman, J.: Moving beyond insularity in the history, philosophy, and sociology of chemistry. Found. Chem. (2017). https://doi.org/10.1007/s10698-017-9290-7 